\title{
Activation of spinal dorsal horn astrocytes by noxious stimuli involves descending noradrenergic signaling
}

\author{
Riku Kawanabe ${ }^{1}$, Kohei Yoshihara', Izuho Hatada ${ }^{2}$ and Makoto Tsuda ${ }^{*}$ (D)
}

\begin{abstract}
Astrocytes are critical regulators of neuronal function in the central nervous system (CNS). We have previously shown that astrocytes in the spinal dorsal horn (SDH) have increased intracellular $\mathrm{Ca}^{2+}$ levels following intraplantar injection of the noxious irritant, formalin. However, the underlying mechanisms remain unknown. We investigated these mechanisms by focusing on the role of descending noradrenergic (NAergic) signaling because our recent study revealed the essential role of the astrocytic $\mathrm{Ca}^{2+}$ responses evoked by intraplantar capsaicin. Using in vivo SDH imaging, we found that the $\mathrm{Ca}^{2+}$ level increase in SDH astrocytes induced by intraplantar formalin injection was suppressed by ablation of SDH-projecting locus coeruleus (LC)-NAergic neurons. Furthermore, the formalin-induced $\mathrm{Ca}^{2+}$ response was dramatically decreased by the loss of $a_{1 A}$-adrenaline receptors (ARs) in astrocytes located in the superficial laminae of the SDH. Moreover, similar inhibition was observed in mice pretreated intrathecally with an $a_{1 A}$-AR-specific antagonist. Therefore, activation of $\mathrm{a}_{1 \mathrm{~A}}$-ARs via descending LC-NAergic signals may be a common mechanism underlying astrocytic $\mathrm{Ca}^{2+}$ responses in the SDH evoked by noxious stimuli, including chemical irritants.
\end{abstract}

Astrocytes, which are abundant glial cells in the CNS, have become increasingly recognized as critical elements regulating neuronal function [1] including somatosensory information processing in the spinal dorsal horn $(\mathrm{SDH})[2,3]$ and brain [4]. By using a method of in vivo $\mathrm{Ca}^{2+}$ imaging in the SDH [5], several studies have shown that SDH astrocytes have increased intracellular $\mathrm{Ca}^{2+}$ levels $\left(\left[\mathrm{Ca}^{2+}\right]_{\mathrm{i}}\right)$ following strong mechanical pressure (pinch) to the hindpaw [6] and intraplantar injection of chemical irritants (capsaicin and formalin) [7, 8], suggesting that $\mathrm{SDH}$ astrocytes respond to noxious stimuli in the periphery. However, the mechanism underlying the increase in astrocytic $\left[\mathrm{Ca}^{2+}\right]_{\mathrm{i}}$ is not fully understood. Our recent study demonstrated that $\left[\mathrm{Ca}^{2+}\right]_{\mathrm{i}}$ increases in

\footnotetext{
*Correspondence: tsuda@phar.kyushu-u.ac.jp

1 Department of Molecular and System Pharmacology, Graduate School of Pharmaceutical Sciences, Kyushu University, 3-1-1 Maidashi, Higashi-ku, Fukuoka 812-8582, Japan

Full list of author information is available at the end of the article
}

SDH astrocytes after intraplantar capsaicin are mediated by the activation of $\alpha_{1 \mathrm{~A}}$-adrenaline receptors $\left(\alpha_{1 A^{-}}\right.$ ARs) through descending noradrenergic (NAergic) neurons from the locus coeruleus (LC) to the SDH [7]. However, whether the $\alpha_{1 \mathrm{~A}}$-AR-mediated descending LCNAergic signals commonly contribute to astrocytic $\mathrm{Ca}^{2+}$ responses evoked by noxious stimuli remains unclear. In this study, we investigated astrocytic $\mathrm{Ca}^{2+}$ responses to noxious irritant formalin using multiple approaches, including in vivo $\mathrm{Ca}^{2+}$ imaging, circuit-specific neuronal ablation, conditional gene knockout, and pharmacological intervention.

For in vivo $\mathrm{Ca}^{2+}$ imaging in $\mathrm{SDH}$ astrocytes, the $\mathrm{Ca}^{2+}$ indicator, GCaMP6m, was selectively expressed in $\mathrm{SDH}$ astrocytes following microinjection of an adenoassociated virus (AAV) vector expressing GCaMP6m under the control of the astrocytic promoter, gfaABC $\mathrm{D}$, into the left $\mathrm{SDH}$ (Additional file 1: Figure S1; Additional file 2), as reported previously [7, 8]. Using GCaMP6mexpressing mice under anesthesia, we confirmed that original author(s) and the source, provide a link to the Creative Commons licence, and indicate if changes were made. The images or other third party material in this article are included in the article's Creative Commons licence, unless indicated otherwise in a credit line to the material. If material is not included in the article's Creative Commons licence and your intended use is not permitted by statutory regulation or exceeds the permitted use, you will need to obtain permission directly from the copyright holder. To view a copy of this licence, visit http://creativecommons.org/licenses/by/4.0/. The Creative Commons Public Domain Dedication waiver (http://creativeco mmons.org/publicdomain/zero/1.0/) applies to the data made available in this article, unless otherwise stated in a credit line to the data. 
intraplantar injection of formalin, but not vehicle, induced robust increases in $\left[\mathrm{Ca}^{2+}\right]_{\mathrm{i}}$ in $\mathrm{SDH}$ astrocytes (Fig. 1a). To examine the involvement of the descending LC-NAergic pathway, we employed a circuit-specific ablation method using diphtheria toxin (DTX) and its receptor (DTR). To ablate SDH-projecting LC-NAergic neurons, AAVretro-Cre was microinjected into the left SDH of wild-type mice, and AAV-FLEX-DTR-EGFP or AAV-FLEX-AcGFP (control) was injected into the bilateral LC (Fig. 1b). In these mice, GFP expression was observed in the $\mathrm{LC}$, and $\mathrm{GFP}^{+} \mathrm{LC}$ neurons were immunolabeled with an antibody for tyrosine hydroxylase $(\mathrm{TH})$, a marker for catecholaminergic neurons (mostly NAergic neurons in the LC) (Fig. 1c). Systemic administration of DTX eliminated $\mathrm{GFP}^{+} \mathrm{LC}$ neurons in mice with AAV-FLEX-DTR-EGFP, but not in those with
AAV-FLEX-AcGFP (Fig. 1c). In GCaMP6m-expressing mice with an ablation of descending LC-NAergic neurons, we found that the percentage of SDH astrocytes with increased $\left[\mathrm{Ca}^{2+}\right]_{\mathrm{i}}$ evoked by intraplantar formalin injection was significantly lower (Fig. 1d). The average trace of $\mathrm{Ca}^{2+}$ responses and the area under the curve (AUC) of $\mathrm{Ca}^{2+}$ traces from individual SDH astrocytes during the first $600 \mathrm{~s}$ after formalin injection were also suppressed. These results indicate that the descending LC-NAergic pathway contributes to formalin-induced astrocytic $\mathrm{Ca}^{2+}$ responses in SDH.

We previously identified $\alpha_{1 \mathrm{~A}}$-AR as an astrocyteexpressing receptor necessary for $\mathrm{Ca}^{2+}$ responses evoked by intraplantar capsaicin [7]. Consistent with our previous study [7], immunohistochemical analysis confirmed that $96.5 \pm 1.9 \%$ of $\mathrm{SDH}$ astrocytes expressed $\alpha_{1 \mathrm{~A}}$-ARs

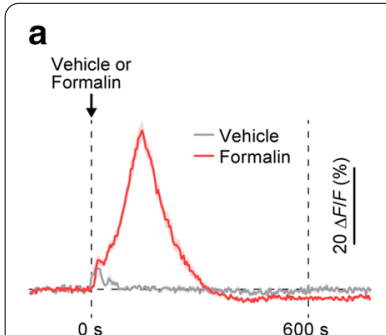

$0 \mathrm{~s}$

c

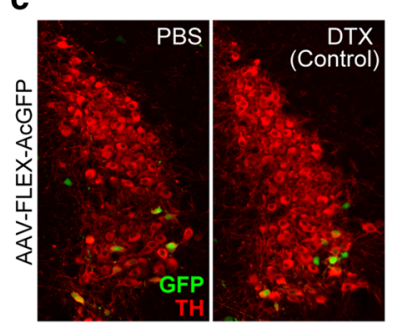

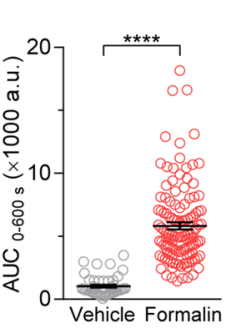
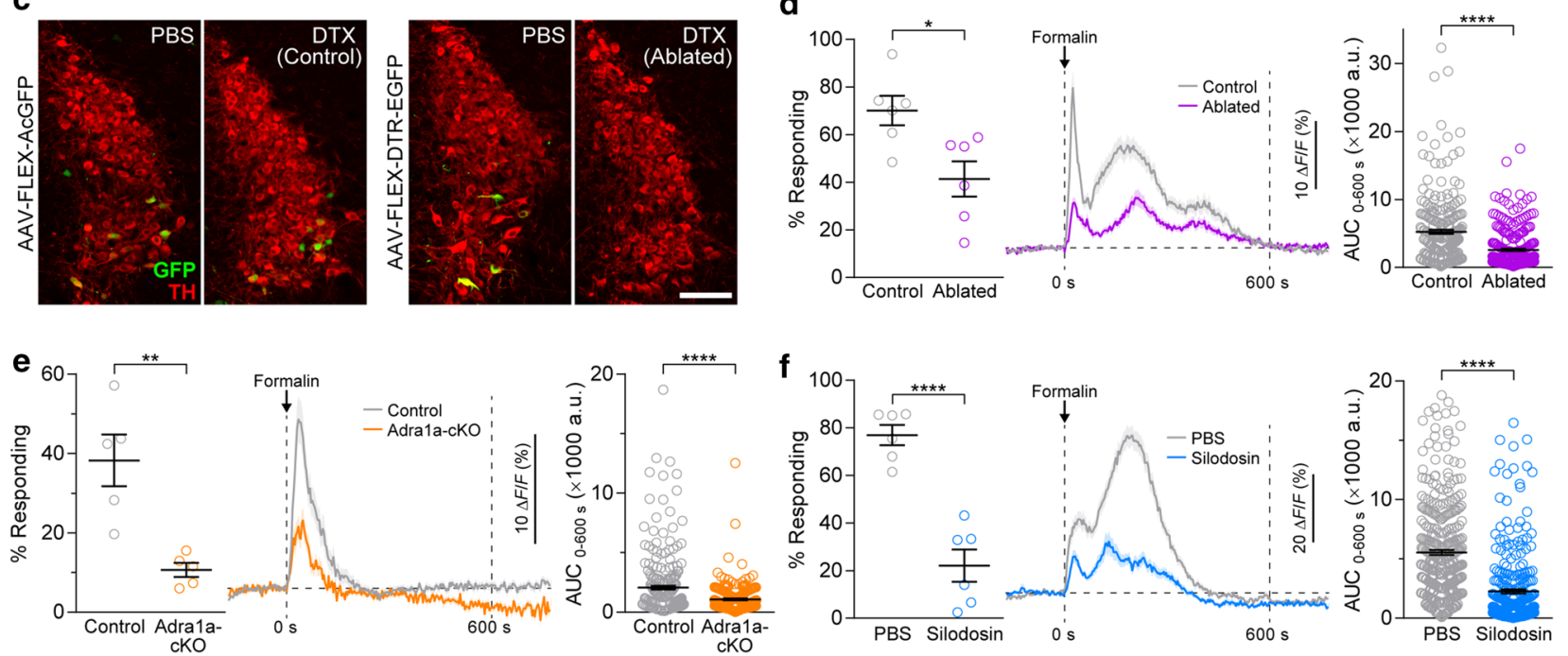

Fig. 1 Intraplantar injection of formalin activates SDH astrocytes via $a_{1 A}$-ARs through descending LC-NAergic signals. a Averaged trace and AUC during the first $600 \mathrm{~s}\left(\mathrm{AUC}_{0-600 \mathrm{~s}}\right.$ ) of astrocytic $\mathrm{Ca}^{2+}$ signals in the SDH after intraplantar injection of vehicle or formalin (vehicle, $n=47 \mathrm{ROIs,} 4$ mice; formalin, $n=123$ ROls, 4 mice, ${ }^{* * * *} P<0.0001$, Mann-Whitney $U$ test). $\mathbf{b}$ Schematic illustration of retrograde transduction strategy in descending LC-NAergic neurons using the FLEX-switch system. c Representative images of LC-NAergic neurons in mice treated with PBS or DTX administration. GFP (green), and TH (red). d-f SDH astrocytic Ca ${ }^{2+}$ responses by formalin in mice with ablation of descending LC-NAergic neurons (d), conditional knockout of $a_{1 A^{-A R s ~ i n ~ H e s 5 ~}}{ }^{+}$astrocytes (Adra1a-CKO; Hes5-CreERT2;Adra1 $a^{\text {flox/flox}}$ ) compared with control mice (control; Adra1 $a^{\text {flox/flox }}$ ) (e), and pretreatment intrathecally with PBS or silodosin (3 nmol) (f). Percentage of responding astrocytes ( $\mathbf{d}$ control, $n=6$ mice; ablated, $n=6$ mice; e: control, $n=5$ mice; Adra1a-cKO, $n=5$ mice; f PBS, $n=6$ mice; silodosin, $n=6$ mice, ${ }^{*} P<0.05$, ${ }^{* *} P<0.01,{ }^{* * * *} P<0.0001$, unpaired $t$-test); averaged trace and AUC (d control, $n=255$ ROls; ablated, $n=263$ ROls; e control, $n=253$ ROls; Adra1a-cKO, $n=224$ ROls; f PBS, $n=364$ ROls; silodosin, $n=296$ ROls, ${ }^{* * *} P<0.0001$, Mann-Whitney U test). Data show the mean \pm SEM 
(Additional file 1: Figure S2). Thus, we examined the role of $\alpha_{1 \mathrm{~A}}$-AR using Hes5-CreERT2;Adra1 $a^{\text {flox/flox }}$ mice (treated with tamoxifen) that lack this receptor in SDH astrocytes, especially localized in superficial laminae [7]. The number of SDH astrocytes with increased $\left[\mathrm{Ca}^{2+}\right]_{\mathrm{i}}$ by formalin in Adrala $a^{\text {flox/flox }}$ control mice (Control) was dramatically decreased in Hes5-CreERT2;Adra1 a flox/flox mice (Adra1a-cKO) (Fig. 1e). The average trace and AUC for $\mathrm{Ca}^{2+}$ responses were also lower in Adrala-cKO mice than in control mice. Adra1a-cKO mice treated with tamoxifen also lack $\alpha_{1 \mathrm{~A}}$-AR expression in brain Hes $5^{+}$ astrocytes [7]. To determine the importance of $\alpha_{1 \mathrm{~A}}$-ARs in the spinal cord, we intrathecally administered the $\alpha_{1 A^{-}}$ AR-specific antagonist, silodosin, before formalin injection. Silodosin-pretreated mice also showed marked inhibition of the formalin-induced astrocytic $\mathrm{Ca}^{2+}$ responses (the percentage of SDH astrocytes with $\left[\mathrm{Ca}^{2+}\right]_{i}$ increases, the average trace of $\mathrm{Ca}^{2+}$ responses, and their AUCs) (Fig. 1f). Taken together, the $\mathrm{Ca}^{2+}$ responses in $\mathrm{SDH}$ astrocytes following formalin injection are mediated by the activation of $\alpha_{1 \mathrm{~A}}$-ARs through descending LC-NAergic signals.

In this study, we demonstrate for the first time that intraplantar injection of the noxious irritant, formalin, activates $\mathrm{SDH}$ astrocytes (especially the $\mathrm{Hes}^{+}$subset) via $\alpha_{1 \mathrm{~A}}$-ARs stimulated by descending LC-NAergic signaling. Previous data showing induction of the neuronal activity marker c-FOS in LC-NAergic neurons [9] supports our findings. Given that astrocytic $\mathrm{Ca}^{2+}$ responses in the SDH after intraplantar capsaicin are mediated by $\alpha_{1 \mathrm{~A}}$-AR-mediated descending LC-NAergic signaling [7], this raises the possibility that this signaling pathway from the LC-NAergic neurons to SDH astrocytes is a common mechanism for astrocytic $\mathrm{Ca}^{2+}$ responses in the SDH evoked by noxious chemical irritants. However, the decrease in the number of responding astrocytes was slightly lower in mice with LC-NAergic neuron ablation than in mice with conditional $\alpha_{1 \mathrm{~A}}$-AR-knockout and silodosin pretreatment. This could be due to incomplete ablation of LC-NAergic neurons projecting to the 4th lumbar $\mathrm{SDH}$ where astrocytic $\mathrm{Ca}^{2+}$ responses were monitored or the involvement of other descending NAergic pathways, for example, from regions A5 and A7 (although the LC is the main source of NA in the SDH [10]). In addition, considering the residual astrocytic $\mathrm{Ca}^{2+}$ responses observed in mice either with genetic knockout or pharmacological blockade of $\alpha_{1 \mathrm{~A}}$-ARs, it seems that other neurotransmitters, such as glutamate, GABA, and ATP, which are known to cause astrocytic $\mathrm{Ca}^{2+}$ elevations [11], may also be involved. Nevertheless, our findings indicate that $\alpha_{1 A^{-}}$ AR-mediated descending LC-NAergic signals are a primary driver of $\mathrm{Ca}^{2+}$ responses in $\mathrm{SDH}$ astrocytes evoked by noxious stimuli.
In this study, there were different patterns of the average traces of $\mathrm{Ca}^{2+}$ responses after intraplantar formalin injection among experiments. The reason for this difference remains unclear. Nevertheless, $\mathrm{Ca}^{2+}$ responses during several minutes after the injection are commonly observed and are consistent with our previous data [8]. However, $\mathrm{Ca}^{2+}$ responses in Adral $a^{\text {flox/flox }}$ and Hes5CreERT2;Adra1 $a^{\text {flox/flox }}$ mice were different from others. It may involve a genetic factor (and/or tamoxifen treatment) because the genetic background of $A d r a 1 a^{\text {flox } /}$ flox mice was derived from BDF1 [(C57BL/6 $\times$ DBA/2) F1] strain and these mice were not fully backcrossed on the C57BL/6 background, while other experiments used C57BL/6 mice.

Formalin is used as a model for acute and persistent inflammatory pain associated with peripheral tissue injury. The role of spinal NAergic signals in formalininduced pain has been examined in many studies [12, 13], but it remains controversial. For example, intrathecal treatment with $\alpha_{2}$-AR agonists reduces formalin pain $[12,14]$, intrathecal treatment with anti-dopamine- $\beta$ hydroxylase antibody-conjugated saporin, which kills SDH-projecting NAergic neurons, attenuates formalin pain [15]. An explanation for this discrepancy may be partly associated with the action of NA in SDH astrocytes. It should be noted that we measured the astrocytic $\mathrm{Ca}^{2+}$ responses for the first $10 \mathrm{~min}$ after formalin injection, a time period that corresponds to acute phase of formalin-induced nociceptive behavior. Further investigations using a tool to manipulate $\mathrm{Ca}^{2+}$ responses specifically in $\mathrm{Hes}^{+} \mathrm{SDH}$ astrocytes will uncover their in vivo role in nociceptive information processing and behaviors evoked by formalin.

\section{Abbreviations}

AAV: Adeno-associated virus; AR: Adrenaline receptor; AUC: Area under the curve; DTR: Diphtheria toxin receptor; DTX: Diphtheria toxin; Hes5: Hairy and enhancer of split 5; LC: Locus coeruleus; NA: Noradrenaline; SDH: Spinal dorsal horn; TH: Tyrosine hydroxylase.

\section{Supplementary Information}

The online version contains supplementary material available at https://doi. org/10.1186/s13041-021-00788-5.

Additional file 1: Figure S1. Immunohistochemical identification of GCaMP6m-expressing cells in the SDH. Spinal cord sections from mice with microinjection of AAV-gfaABC $C_{1}$-GCaMP $6 m$ into the SDH were immunostained by cell-type-specific markers (SOX9 and GFAP, astrocytes; NeuN, neurons; IBA1, microglia; APC, oligodendrocytes) (red). Note that GCaMP6m-expressing cells (green) were positive to astrocyte markers (SOX9 and GFAP) but were negative to other markers (NeuN, IBA1 and APC). Scale bar, $20 \mu \mathrm{m}$. Figure $\mathbf{S 2}$. Immunohistochemical analysis of $a_{1 A}$-AR expression in SDH astrocytes. Immunofluorescence of $a_{1 A^{-}}-A R$ (green) and GFAP (magenta) in the SDH of wild-type mice. Scale bar, 20 $\mu \mathrm{m}$. Percentage of $\mathrm{a}_{1 \mathrm{~A}^{-}}-\mathrm{AR}^{+}$astrocytes per total SDH astrocytes $(n=166$ cells, 9 slices from 3 mice). Data show the mean \pm SEM. 


\section{Additional file 2. Methods.}

\section{Acknowledgements}

We thank the University of Pennsylvania vector core for providing pZac2.1, pAAV2/9, and pAd DeltaF6 plasmids and Prof. Verdon Taylor (University of Basel, Basel, Switzerland) for providing Hes5-CreERT2 mice. We would like to thank Editage (www.editage.com) for English language editing.

\section{Authors' contributions}

RK designed experiments, performed almost all experiments, analyzed the data and wrote the manuscript. KY designed experiments and performed intrathecal drug administration. IH provided Adral $a^{\text {flox/flox }}$ mice. MT conceived this project, supervised the overall project, designed experiments and wrote the manuscript. All authors read and approved the final manuscript.

\section{Funding}

This work was supported by JSPS KAKENHI Grant Numbers JP19K22500, JP19H05658, JP20H05900 (M.T.), by the Core Research for Evolutional Science and Technology (CREST) program from AMED under Grant Number JP20gm0910006 (M.T.), and by Platform Project for Supporting Drug Discovery and Life Science Research (Basis for Supporting Innovative Drug Discovery and Life Science Research (BINDS)) from AMED under Grant Number JP20am0101091 (M.T.). K.Y. was research fellows of the JSPS (19J21063).

\section{Availability of data and materials}

All data generated or analyzed during this study are included in this published article and its Additional file.

\section{Declarations}

\section{Ethics approval and consent to participate}

Not applicable.

\section{Consent for publication}

Not applicable.

\section{Competing interests}

All authors declare that they have no competing interests.

\section{Author details}

${ }^{1}$ Department of Molecular and System Pharmacology, Graduate School of Pharmaceutical Sciences, Kyushu University, 3-1-1 Maidashi, Higashi-ku, Fukuoka 812-8582, Japan. ${ }^{2}$ Laboratory of Genome Science, Biosignal Genome Resource Center, Institute for Molecular and Cellular Regulation, Gunma University, 3-39-15 Showa-machi, Maebashi, Gunma 371-8512, Japan.

\section{References}

1. Ben Haim L, Rowitch DH. Functional diversity of astrocytes in neural circuit regulation. Nat Rev Neurosci. 2017;18(1):31-41.

2. Ji RR, Donnelly CR, Nedergaard M. Astrocytes in chronic pain and itch. Nat Rev Neurosci. 2019:20(11):667-85.

3. Tsuda M. Modulation of pain and itch by spinal glia. Neurosci Bull. 2018;34(1):178-85.

4. Kim SK, Hayashi H, Ishikawa T, Shibata K, Shigetomi E, Shinozaki Y, et al. Cortical astrocytes rewire somatosensory cortical circuits for peripheral neuropathic pain. J Clin Invest. 2016;126(5):1983-97.

5. Farrar MJ, Bernstein IM, Schlafer DH, Cleland TA, Fetcho JR, Schaffer CB. Chronic in vivo imaging in the mouse spinal cord using an implanted chamber. Nat Methods. 2012;9(3):297-302.

6. Sekiguchi KJ, Shekhtmeyster P, Merten K, Arena A, Cook D, Hoffman E, et al. Imaging large-scale cellular activity in spinal cord of freely behaving mice. Nat Commun. 2016;7:11450.

7. Kohro Y, Matsuda T, Yoshihara K, Kohno K, Koga K, Katsuragi R, et al. Spinal astrocytes in superficial laminae gate brainstem descending control of mechanosensory hypersensitivity. Nat Neurosci. 2020;23(11):1376-87.

8. Yoshihara K, Matsuda T, Kohro Y, Tozaki-Saitoh H, Inoue K, Tsuda M. Astrocytic $\mathrm{Ca}^{2+}$ responses in the spinal dorsal horn by noxious stimuli to the skin. J Pharmacol Sci. 2018;137(1):101-4.

9. Imbe H, Okamoto K, Donishi T, Kawai S, Enoki K, Senba E, et al. Activation of ERK in the locus coeruleus following acute noxious stimulation. Brain Res. 2009;1263:50-7.

10. Li Y, Hickey L, Perrins R, Werlen E, Patel AA, Hirschberg S, et al. Retrograde optogenetic characterization of the pontospinal module of the locus coeruleus with a canine adenoviral vector. Brain Res. 2016;1641(Pt B):274-90.

11. Bazargani N, Attwell D. Astrocyte calcium signaling: the third wave. Nat Neurosci. 2016:19(2):182-9.

12. Pertovaara A. Noradrenergic pain modulation. Prog Neurobiol. 2006;80(2):53-83.

13. Llorca-Torralba M, Borges G, Neto F, Mico JA, Berrocoso E. Noradrenergic Locus Coeruleus pathways in pain modulation. Neuroscience. 2016:338:93-113.

14. Takano Y, Yaksh TL. Characterization of the pharmacology of intrathecally administered alpha-2 agonists and antagonists in rats. J Pharmacol Exp Ther. 1992;261(2):764-72.

15. Martin WJ, Gupta NK, Loo CM, Rohde DS, Basbaum Al. Differential effects of neurotoxic destruction of descending noradrenergic pathways on acute and persistent nociceptive processing. Pain. 1999;80(1-2):57-65.

\section{Publisher's Note}

Springer Nature remains neutral with regard to jurisdictional claims in published maps and institutional affiliations.
Ready to submit your research? Choose BMC and benefit from:

- fast, convenient online submission

- thorough peer review by experienced researchers in your field

- rapid publication on acceptance

- support for research data, including large and complex data types

- gold Open Access which fosters wider collaboration and increased citations

- maximum visibility for your research: over $100 \mathrm{M}$ website views per year

At BMC, research is always in progress.

Learn more biomedcentral.com/submissions 